\title{
O DESENVOLVIMENTO DO PROJETO TERRÁRIO NA FORMAÇÃO INICIAL DE PROFESSORES DE CIÊNCIAS e BIOLOGIA: CONSIDERAÇÕES SOBRE A ATIVIDADE DO PIBID
}

\author{
André Maciel da Silva ${ }^{1}$ \\ João Henrique de Oliveira Pereira ${ }^{2}$ \\ Antonio Fernandes Nascimento Junior ${ }^{3}$
}

\begin{abstract}
RESUMO
O trabalho relata atividades desenvolvidas no projeto intitulado Terrário-Macaquices que foi desenvolvido como espaço de formação de professores no Subprojeto de Biologia do Programa de Iniciação à Docência (PIBID) da Universidade Federal de Lavras. As atividades procuraram viabilizar aos licenciandos bolsistas do programa, a experiência de construir junto estudantes de escolas da rede pública do município de Lavras (MG), conhecimentos da ecologia e também problematizar questões ambientais, tais como a inserção de uma espécie de macaco no ambiente urbano e o desiquilíbrio ambiental e social da construção de uma barragem. Para isso, houve a montagem de terrários que possibilitaram a construção do conceito de fatores bióticos e abióticos, além da importância desses fatores na constituição do ecossistema. Em seguida, foi utilizado um varal de fotografias para tratar de desequilíbrios ecológicos causados pela ausência de alguns desses fatores. A partir dessa questão, foi possível trabalhar questões relacionadas à Educação Ambiental, tal como os impactos socioambientais. Ao final do projeto, os bolsistas do PIBID, participantes do desenvolvimento do projeto, fizeram uma avaliação do processo, argumentando a sua realização em relação a sua formação como professores. A partir da análise de suas falas foi possível perceber a importância que atribuíram a utilização de metodologias não expositivas e da inserção da educação ambiental na formação dos professores.
\end{abstract}

PALAVRAS-CHAVE: Formação de professores. Educação Ambiental. Ensino de Ciências e Biologia.

\footnotetext{
${ }^{1}$ Graduando em Ciências Biológicas (Licenciatura), Universidade Federal de Lavras, MG. andremaciel_29@hotmail.com

${ }^{2}$ Graduando em Ciências Biológicas (Licenciatura), Universidade Federal de Lavras, MG. in_91@hotmail.com

${ }_{3}$ Professor Adjunto do Departamento de Biologia, Universidade Federal de Lavras, MG. toni_nascimento@yahoo.com.br
} 
da Alta Paulista

\title{
THE DEVELOPMENT OF THE TERRARIUM PROJECT ON THE STARTING FORMATION OF TEACHERS OF SCIENCES AND BIOLOGY: CONSIDERATIONS ABOUT THE PIBID ACTIVITY
}

\begin{abstract}
This paper reports activities developed on the project called Terrário-Macaquices, which was developed as an space for teacher formation on the subproject of biology of the Program of Introduction to Teaching (PIBID) on the Universidade Federal de Lavras (MG). The activities sought to viabilize to the scholarship students of the program the experience of building, alongside students of public schools of the city of Lavras (MG), knowledge of ecology and problematize environmental questions, like the insertion of a specie of monkey on urban environment and the environmental and social imbalance of the construction of a barrage. For this, there was the assembly of terrariums which possibilited the construction of the concepts of biotic and abiotic factors, and also the importance of these factors on the constitution of the ecossystem. After this, it was used a string with fotographs to talk about ecological imbalances caused by the abcense of some of these factors. From this question, it was possible to discuss questions related to Environmental Education, like socio-environmental impacts. At the end of the project, the scholarship students of PIBID, who took part on the development of the project, did an evaluation of the process, arguing its realization in relation to their formation as teachers. From the analysis of their speeches it was possible to realize the importance they have given to the use of nonexpositive metodologies and of the insertion of environmental education on the formation of teachers.
\end{abstract}

KEY-WORDS: Teachers formation. Environmental Education. Biology and Sciences teaching.

\section{EL DESARROLLO DEL PROYECTO TERRÁRIO EN LA FORMACIÓN INICIAL DE PROFESORES DE CIENCIAS Y BIOLOGÍA: CONSIDERACIONES SOBRE LA ACTIVIDAD DEL PIBID}

\begin{abstract}
RESUMEN
Las actividades de los informes de papel en el proyecto titulado terrario-macaquices se desarrolló como espacio de la formación del profesorado en lo proyecto Programa de Iniciación para la Enseñanza de Biología (PIBID) de la Universidad Federal de Lavras. Las actividades buscaron mostrar para os estudiantes del programa, la experiencia de la construcción, junto a estudiantes de escuelas públicas de la ciudad de Lavras (MG), conocimiento de ecología y también discutir temas ambientales, tales como la inclusión de una especie de mono en el medio urbano y el desequilibrio ambiental y social de la construcción de una presa. Para esto, fueran montados terrarios que permitió la construcción del concepto de factores bióticos y abióticos y la importancia de estos factores en la constitución del ecosistema. Entonces, fuera utilizado un tendedero de fotografías para tratar los desequilibrios ecológicos causados por la ausencia de algunos de estos factores. A partir de ese momento, era posible trabajar temas relacionados con la educación ambiental como los impactos sociales y ambientales. Al final del proyecto, los estudiantes del PIBID, participantes en el desarrollo del proyecto, hicieron una evaluación del proceso, argumentando sus logros en relación con su formación como maestros. A partir del análisis de su discurso fue posible darse cuenta de la importancia atribuida a la utilización de metodologías no expositivos y la inclusión de la educación ambiental en la formación del profesorado.
\end{abstract}

PALABRAS-CLAVE La formación del profesorado. Educación Ambiental. Enseñanza de la ciência y biologia. 


\section{INTRODUÇÃO E OBJETIVOS}

A relação entre os seres humanos e o meio ambiente é bastante problemática e conflituosa. Aspectos econômicos tem se sobreposto à qualidade de vida coletiva (SILVA; CALIXTO, 2013), e a necessidade de "progresso" a todo o custo característico de nossa sociedade tem gerado diferentes impactos sociais e ambientais, e como afirma Schmidheiny (2002), não existe desenvolvimento econômico sem prejuízo da natureza. Porém, ainda de acordo com o autor, é possível administrar essa relação, de modo a minimizar os danos.

Nesse sentido, percebe-se a importância de se inserir a Educação Ambiental (EA) na Educação Básica de modo a estimular a aprendizagem de conhecimentos que viabilizam a compreensão e a reflexão dos alunos acerca da relação entre natureza e sociedade. Visando contemplar esta necessidade surge o Tema Transversal Meio Ambiente presente nos Parâmetros Curriculares Nacionais (PCN) que se propõe a viabilizar a inserção da EA nos currículos da Educação Básica, de forma transversal. Segundo o PCN (BRASIL, 1998), o aluno deve perceber-se integrante e agente transformador do ambiente, contribuindo ativamente para sua melhoria. No entanto, apenas a proposição do currículo não é suficiente, para que a EA esteja presente no conteúdo das escolas é necessário que ela seja inserida no processo de formação inicial de professores. Neste sentido, segundo Loureiro (2004), além da apropriação do conhecimento científico, os licenciandos precisam construir uma visão crítica que permita uma análise acerca do tema Meio Ambiente.

Esta é uma das preocupações formativas do Programa Institucional de Bolsas de Iniciação à Docência (PIBID) de biologia, da Universidade Federal de Lavras MG (UFLA). O foco é na formação inicial e continuada, abordando junto aos estudantes do ensino básico algumas questões ambientais e suas implicações na sociedade. Essa questão é defendida por Lima (2009), justificando que tal reflexão permite reconhecer os desafios socioambientais da sociedade moderna, ultrapassando os limites dos campos de conhecimento e reconhecendo que as ações humanas também influenciam as questões ambientais.

Outro problema enfrentado pelos professores e, que também é uma preocupação do PIBID de Biologia da UFLA, é a limitação do ensino por meio de 
práticas expositivas. Segundo Yamazaki e Yamazaki (2006), essas práticas são consideradas entediantes, cansativas e pouco eficazes na construção do conhecimento. Nessa perspectiva, ainda segundo os autores, é necessário tornar os alunos parte do processo, possibilitando maior interesse dos alunos no processo. Para isso, torna-se necessário que o professor busque utilizar estratégias pedagógicas diferenciadas que tragam o conteúdo à realidade dos alunos.

Tendo como base essas perspectivas, o PIBID de Biologia desenvolveu um projeto denominado Terrário - Macaquices com o objetivo de inserir a Educação Ambiental na formação dos professores e, consequentemente, na formação dos alunos das escolas públicas. Para tal, foi utilizada uma estratégia pedagógica alternativa, o terrário, aliado a um varal de fotografias. O presente trabalho tem como objetivo descrever as etapas do projeto além de avaliá-lo quanto à sua potencialidade na formação dos professores.

\section{DESENVOLVIMENTO}

O desenvolvimento do projeto foi dividido em três momentos: preparação e planejamento do projeto, ação nas salas e avaliação do projeto pelos bolsistas.

\section{Primeiro momento: preparação e planejamento do projeto}

O Projeto Terrário - Macaquices foi planejado de forma superar a restrição da prática de ensino expositiva, criando assim uma metodologia alternativa com maior participação do aluno da escola durante as atividades. Para isso, foram realizadas discussões coletivas (pelo coordenador do projeto, bolsistas e professores supervisores) para a decisão sobre o tema e sobre as estratégias utilizadas. Assim, o conceito biológico central foi o de "ecossistema", o que dialogou com a Educação Ambiental e com a discussão sobre a presença dos "micos estrelas" (Callithrix penicillata) nas áreas urbanas e os motivos pelos quais isso está acontecendo. Como estratégia pedagógica, optamos pela realização de uma problematização a partir da produção de um terrário, uma vez que representa um micro ecossistema, e de um varal de fotografias 
Os materiais utilizados foram de baixo custo e de fácil acesso. Os terrários foram construídos em garrafas PET, utilizados brita, areia e terra para representar a formação do solo, além de feijão e alpiste, para representar a cobertura vegetal de um ecossistema. A construção do varal de imagens foi feita coletivamente pelos bolsistas, tanto na escolha como na disposição das fotos. Assim, foram utilizadas imagens de casas, árvores, do mico estrela, do sol, de rios e, pensando na regionalização do projeto, uma imagem de uma usina hidrelétrica existente na região de Lavras.

As etapas para o desenvolvimento do projeto foram decididas para serem feitas em duas por semanas. Na primeira semana o terrário foi construído e problematizado, chegando ao conceito de ecossistema. $\mathrm{Na}$ segunda foram discutidos os impactos socioambientais presentes em um ecossistema, através do varal de imagens e dos terrários.

\section{Segundo momento: ação nas salas}

A construção de terrários: foram introduzidas questões relacionadas ao conceito de ecossistema (figura 1). Para isso, durante a montagem dos terrários, foi falado com os alunos sobre os fatores bióticos e abióticos presentes nos ecossistemas. A partir dessa discussão, os alunos chegaram a estes conceitos, podendo assim iniciar a construção dos terrários. Foram montados no total cinco terrários por sala (figura 2), três deles representando um ecossistema terrestre, tanto com fatores bióticos quanto abióticos, um apenas com fatores bióticos e outro apenas com fatores abióticos. Após a montagem dos terrários a aula foi finalizada.

Figura 1. Bolsistas do PIBID contextualizando o terrário.

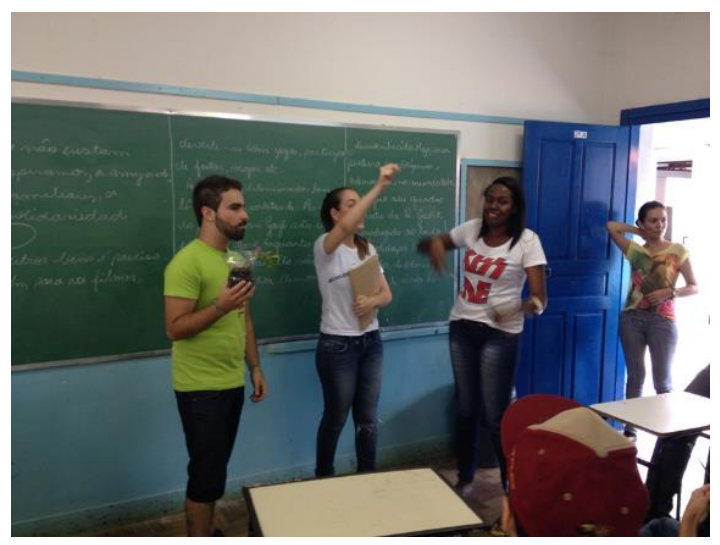

Fonte: PIBID, 2013. 
Figura 2. Construção dos terrários.

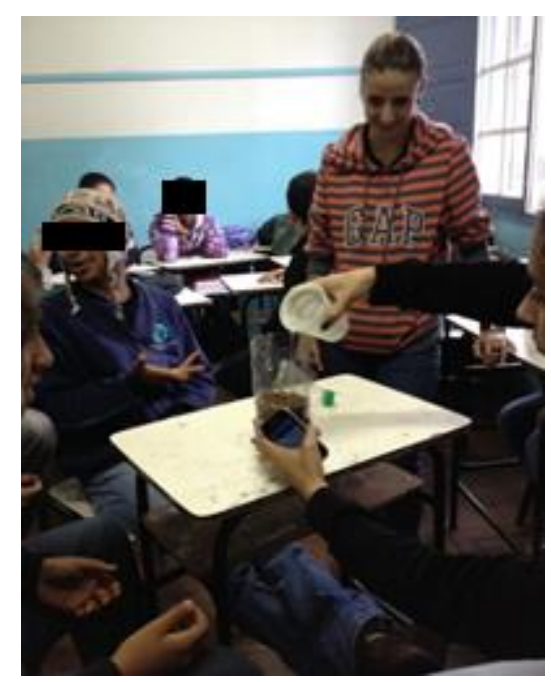

Fonte: PIBID, 2013.

Na segunda aula, na semana seguinte à construção do terrário, os bolsistas do PIBID voltaram às salas de aula para discutir sobre o que havia acontecido com os terrários. Foi mostrado aos alunos que nos terrários que continham tanto os fatores bióticos quanto os abióticos, a vegetação cresceu e o terrário se manteve. Já naqueles que continham apenas fatores bióticos e nos que continham apenas fatores abióticos, não ocorreu nada. A partir desta etapa de observação dos terrários, foi possível concluir com os alunos que só existe um ecossistema quando há uma interação e equilíbrio entre fatores bióticos e abióticos (figura 3).

Figura 3. Discussão sobre os terrários montados na semana anterior.

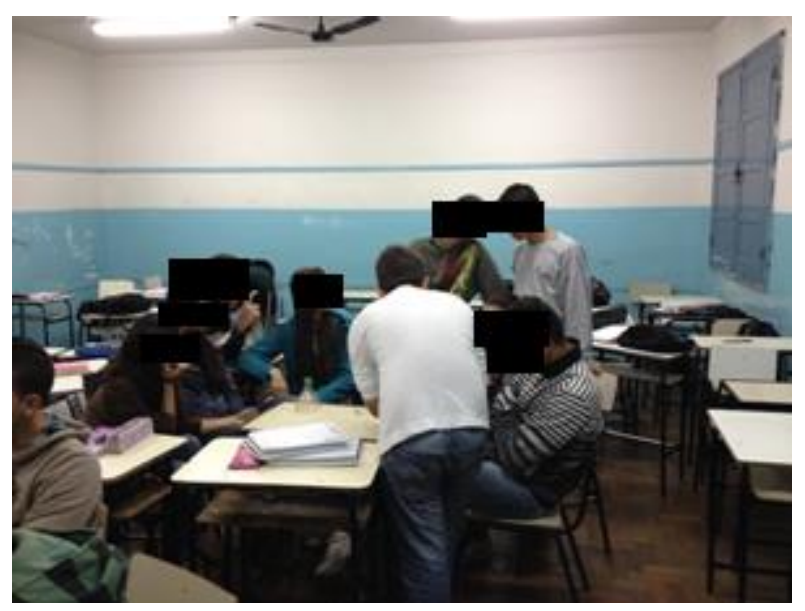

Fonte: PIBID, 2013. 
Na sequência foi montado um varal de fotografias contendo imagens de um rio, uma árvore, um exemplar de mico estrela e uma imagem do sol. Após a montagem do varal, os bolsistas retiraram as fotos do varal, uma por vez, perguntando aos alunos o que aconteceria ao ecossistema se aquele fator fosse retirado, mostrando mais uma vez que a retirada de um desses fatores causa algum tipo de desequilíbrio no meio ambiente (figura 4).

Figura 4. Discussão dos impactos socioambientais a partir do varal de imagens.

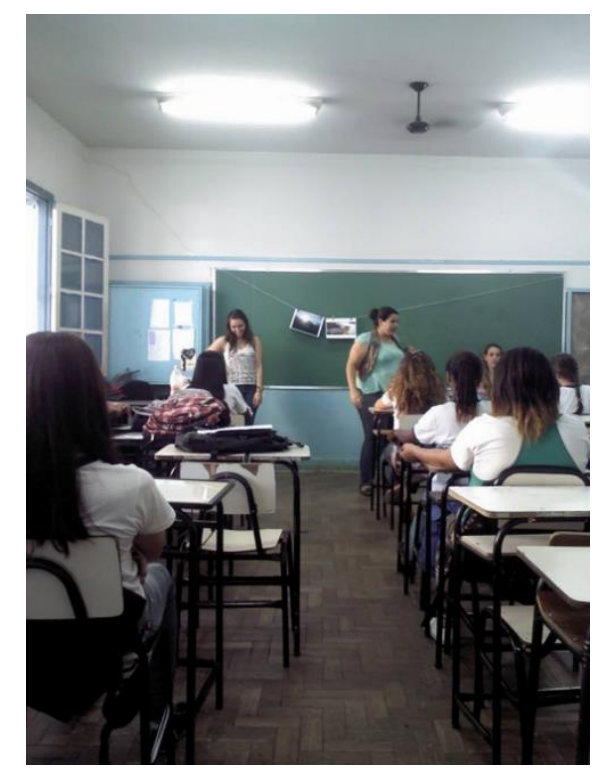

Fonte: PIBID, 2013.

Em seguida, os bolsistas colocaram novamente as fotos no varal e substituíram a imagem do rio pela imagem de uma hidrelétrica. Nesta etapa, foi problematizada a consequência que a construção de uma hidrelétrica traria para aquele ecossistema. Foi discutido com os alunos que a construção dessa usina causaria impactos ambientais, diminuindo a mata existente na região e causando alterações nas condições do rio. Nesse sentido, foi explicado aos alunos que não são os micos estrelas que estão invadindo a área urbana e sim o contrário, os homens estão cada vez mais destruindo matas e florestas, fazendo com que a área de vida desses animais reduza, fazendo com que tenham que procurar recursos na cidade.

Para finalizar esta etapa, foi perguntado aos alunos se a construção da hidrelétrica afeta apenas aquela espécie, problematizando assim que além dos impactos ambientais, há também por trás das hidrelétricas impactos na população 
humana que vive no local, impactos sociais. Foi falado que esse tipo de impacto ocorre uma vez que, para a construção das usinas, as pessoas que habitam as áreas no entorno da construção são desapropriadas de suas terras e realocadas em outros locais, abandonando assim sua tradição cultural e social.

\section{Terceiro momento: avaliação do projeto pelos bolsistas}

Após a finalização do projeto, foi proposta uma avaliação para a prática. Neste momento, os bolsistas deveriam responder à questão:

Qual a importância do projeto para sua formação como professor?

Seguem as transcrições das avaliações realizadas. Nessas avaliações, os bolsistas serão representados pela letra "P" (Pessoa).

P1: "A atividade contribuiu muito para minha formação docente, pela vivencia mais prolongada na escola, que possibilitou a mim refletir mais sobre a estrutura de ensino, mas também pelo desenvolvimento das atividades utilizando estratégias pedagógicas variadas, incrementando meu repertorio didático".

P2: "A atividade auxilia no entendimento, nas dificuldades e realidade do dia-a-dia da escola nos aproximando do papel de educador".

P3: "O subprojeto foi muito importante por possibilitar inserir a educação ambiental crítica na realidade escolar, algo que na maioria das vezes é colocado de maneira superficial, mostrando que eles são parte da natureza".

P4: "Teve relevância como futuro professor por ter aprendido estratégias pedagógicas diferentes das habituais, contribuindo para a aproximação entre professor e aluno".

P5: "Foi muito importante para minha formação como futura professora, pois percebi que usando ferramentas pedagógicas como o terrário fica mais simples ensinar 
conteúdos e desperta interesse nos alunos, tornando a atividade mais prazerosa e não expositiva".

P6: "O subprojeto terrário-macaquices proporcionou o entendimento de que é possível atuar na formação de professores críticos em relação às questões socioambientais, utilizando estratégias pedagógicas não expositivas".

P7: "O projeto serviu como experiência dentro da sala de aula, na aplicação de uma metodologia diferenciada".

P8: "Resumo o projeto como fonte de aprendizagem e aquisição de experiência. $E$ num aspecto pessoal como uma forma de vencer inseguranças".

P9: “Essa atividade me provou como é possível atingir uma maior parte dos alunos, usando a metodologia usada e o interesse dos alunos".

\section{DISCUSSÃO}

O método avaliativo utilizado foi o discurso. Segundo Macedo et al. (2008), por meio deste instrumento o sujeito revela sua compreensão sobre o contexto buscando termos para a produção do discurso. Nesse sentido, ao avaliar o discurso dos alunos que avaliaram a prática, foi possível ressaltar algumas questões. Foi possível perceber que nas falas P1, P2, P7 e P8 os bolsistas destacaram a importância da vivência e experiência do professor em formação na sala de aula, aproximando-o de seu futuro como professor. Essa afirmação se relaciona com as ideias de Pimenta e Lima (2004), uma vez que, segundo os autores, durante o processo de formação inicial de professores deve-se estimular a vivência dos mesmos na escola, possibilitando a construção e reflexão e de fortalecimento da identidade docente. Ainda nesse sentido, Andrade (2005) diz que ao possibilitar uma experiência aos professores em formação na escola, é possível confrontar formulações teóricas e os problemas da realidade escolar, possibilitando a compreensão dessa realidade. 
Foi possível perceber ainda que, segundo os relatos P1, P4, P5, P6, P7 e P9, a importância do projeto foi no sentido de aprender e utilizar estratégias pedagógicas alternativas e não expositivas, despertando o interesse dos alunos e aproximandoos da prática. Essas questões se relacionam diretamente com a pedagogia progressista. Segundo Gonçalves et al. (2012), essa tendência pedagógica valoriza o pensamento crítico do aluno, exigindo uma pluralidade de metodologias de ensino. É possível perceber na fala desses autores que é necessário conhecer e explorar melhor as diversas metodologias de ensino, podendo contribuir para o estímulo do pensamento crítico dos alunos. Ainda nessa perspectiva, segundo Yamazaki e Yamazaki (2006) é necessário que os professores abandonem a limitação das práticas expositivas, envolvendo o aluno e trazendo os conteúdos à sua realidade. Para isso, torna-se necessário que o professor busque utilizar estratégias pedagógicas diferenciadas.

Além disso, nas avaliações P3 e P6, foi possível perceber que a importância do projeto foi inserir a Educação Ambiental Crítica tanto na formação de professores quanto de alunos. Para P3, é importante que a temática seja inserida na escola para mostrar ao aluno que ele também é parte da natureza. Tal perspectiva é trazida pelos Parâmetros Curriculares Nacionais (BRASIL, 1998) através do tema transversal Meio Ambiente. Segundo o documento, os alunos devem perceber-se como integrantes do meio ambiente e também como seus agentes transformadores. Já para P6, a importância se dá na inserção da temática na formação de professores críticos em relação às questões socioambientais. Essa perspectiva tem comum acordo com o pensamento de Loureiro (2004). Segundo o autor, ao inserir a Educação Ambiental Crítica na formação de professores é possível quebrar a dicotomia natureza/sociedade, podendo perceber que os impactos ambientais também influenciam na sociedade.

\section{CONCLUSÃO}

A partir dos relatos dos bolsistas do PIBID foi possível perceber que o projeto Terrário/Macaquices teve grande importância na formação inicial desses professores, possibilitando vivências em sala de aula e também o contato com a pedagogia progressista e novas estratégias pedagógicas, contribuindo para seu 
futuro como professor. Nessa perspectiva, foi possível notar que os bolsistas perceberam a importância dessas questões, uma vez que, utilizando-as, relataram que a aula se tornou mais dinâmica e participativa, melhorando a relação entre aluno e professor e, consequentemente, aproximando os alunos do conhecimento. Nesse sentido, é possível concluir que, justamente por terem essa capacidade, torna-se necessária a busca por estratégias pedagógicas alternativas.

Além disso, foi possível perceber através dos relatos a importância de inserir a Educação Ambiental Crítica na formação de professores, contribuindo para a construção de uma consciência crítica acerca dos impactos socioambientais e possibilitando melhor domínio dos professores em formação sobre o tema, fazendo com que o assunto possa ser tratado em sala de aula de forma crítica e reflexiva.

\section{REFERÊNCIAS BIBLIOGRÁFICAS}

ANDRADE, A. A. M. O estágio supervisionado e a práxis docente, 2005. [on-line]. In: Arnon de Andrade - Site Pessoal. Disponível em http://www.educ.ufrn.br/arnon. Internet. Acessado em 10/04/2015.

BRASIL. Ministério de Educação. Parâmetros Curriculares Nacionais: terceiro e quarto ciclos: Temas Transversais. Secretaria de Ensino Fundamental. Brasília: MEC/SEF, 1998.

GONÇALVES, L. V.; CORTEZ, M. T. J; SANT'ANA, C. R. O; NASCIMENTO JUNIOR, A. F. Utilização do teatro de fantoches como prática de ensino: um relato de experiência do PIBID de biologia da universidade federal de Lavras, MG. Revista de Ensino de Biologia da Associação Brasileira de Ensino de Biologia (SBEnBio), v. 5, p. 1-10, 2012.

LIMA, G. F. C. Educação ambiental crítica: do socioambientalismo às sociedades sustentáveis. Educação e Pesquisa, São Paulo, v. 35, n. 1, p. 146-163, jan. /abr., 2009.

LOUREIRO, C. F. B. Educar, participar e transformar em educação ambiental. Revista Brasileira de Educação Ambiental, Brasília: Rede Brasileira de Educação Ambiental, 2004.

MACEDO, L.C.; LAROCCA, L. M.; CHAVES, M. M. N.; MAZZA, V. A. ANÁLISE DE DISCURSO: uma reflexão para pesquisar em saúde. Interface. Comunicação, Saúde e Educação, v. 12, p. 649-657, 2008.

PIMENTA, S. G.; LIMA, M. S. L. Estágio e Docência. 7. ed. São Paulo: Cortez Editora, 2004. v. 1. 296p.

SCHMIDHEINY, S. Cambiando el rumbo: uma perspectiva global del empresariado para el desarrollo y el médio ambiente. Mexico: Fondo de Cultura Economica, 1992.

SILVA, E. L.; CALIXTO, P.M. Educação ambiental na escola: curso de formação para professores. VI Mostra Nacional de Iniciação Científica e Tecnológica Interdisciplinar. Camboriú, 2013.

YAMAZAKI, S. C.; YAMAZAKI, R. M. de O. Sobre o uso de metodologias alternativas para o ensinoaprendizagem de ciências. Em: Anais da III Jornada de Educação da Região da Grande Dourados, 2006, Dourados. 